\title{
Langkah strategis pengembangan indigenous tourism: Studi kasus di Kabupaten Kepulauan Selayar
}

\author{
Strategic efforts in developing indigenous tourism: \\ A case study in Selayar Island Regency
}

\author{
Ilham Junaid \\ Politeknik Pariwisata Makassar. \\ Jalan Gunung Rinjani, Metro Tanjung Bunga, Kota Mandiri, Sulawesi Selatan \\ E-mail: illank77@yahoo.co.id
}

\begin{abstract}
Indigenous tourism is a relatively new concept for tourism stakeholders and has not become a priority to encourage local tourism potential. The lack of information and previous study about the concept of indigenous tourism and an understanding of the concept make tourism destination focused only in promoting local culture. Therefore, this research aims to identify: 1) the potential of Bitombang and Pandai Besi village in supporting indigenous tourism in Selayar Regency; 2) strategic steps required in supporting Selayar regency through indigenous tourism concept; and 3) actions to take for stakeholders to achieve development goals and achieving balance between indigenous tourism and sustainable tourism. Approach used in this study is feature of qualitative study which able to lead researcher in understanding indigenous tourism in Selayar Regency. To gather the data, researcher conducted interview to the society, government staff, and local communities in Selayar who possess adequate comprehension about the tourism circumstances, and Selayar people sociocultural condition. There are 8 choosen informants who are originally Selayar residents. The research shows that Bitombang and Pandai Besi Old Village are important assets in supporting the development of indigenous tourism, aside from another tourism potential. Therefore, study about history and cultural value of indigenous people, procurement of local tour guide, initiation from environmental organization, and travel route map for tourist are essential. Government's role is also strongly expected to facilitate various communities to take part in the development of indigenous tourism.
\end{abstract}

Keywords: indigenous tourism, Selayar, Bitombang Old Village, Pandai Besi

\begin{abstract}
Abstrak
Indigenous tourism masih merupakan istilah baru bagi kebanyakan stakeholder pariwisata di daerah sehingga belum menjadi prioritas dalam mendorong potensi daerah. Terbatasnya informasi atau kajian mengenai konsep indigenous tourism serta pemahaman mengenai indigenous tourism menjadikan daerah-daerah wisata atau destinasi wisata hanya terfokus pada mempromosikan budaya daerah. Oleh karena itu, penelitian ini bertujuan untuk mengidentifikasi 1) potensi Perkampungan Bitombang dan Pandai Besi dalam mendukung indigenous tourism di Kabupaten Selayar 2) tahap atau langkah-langkah strategis dalam menunjang Kabupaten Selayar melalui konsep indigenous tourism 3) upaya yang harus dilakukan oleh stakeholder daerah dalam mencapai tujuan pengembangan dan penyeimbangan indigenous tourism dan pariwisata berkelanjutan (sustainable tourism). Pendekatan studi kasus yang merupakan feature penelitian kualitatif menuntun peneliti dalam memahami indigenous tourism di Kabupaten Selayar. Metode pengumpulan data dilakukan melalui wawancara ke masyarakat, staf pemerintah bidang pariwisata serta kelompok masyarakat yang memiliki pemahaman mengenai kondisi kepariwisataan, sosial budaya masyarakat di Kabupaten Selayar. Informan berjumlah 8 orang yang merupakan penduduk asli Kabupaten Selayar. Penelitian menunjukkan bahwa Perkampungan Tua Bitombang dan Pandai Besi menjadi kekuatan penting dalam mendukung pengembangan indigenous tourism selain potensi pariwisata lainnya. Karena itu, langkah-langkah seperti kajian tentang sejarah dan nilai-nilai budaya indigenous people, pembantuan (fasilitasi) ke pemandu wisata lokal, inisiasi organisasi lingkungan, budaya dan pariwisata serta pembuatan rute perjalanan untuk wisatawan sangat penting dilakukan untuk mendukung indigenous tourism di Kabupaten Selayar. Peran pemerintah sangat diharapkan dalam memfasilitasi berbagai kelompok masyarakat untuk terlibat dalam mengembangkan indigenous tourism.
\end{abstract}

Kata kunci: indigenous tourism, Selayar, Perkampungan Bitombang, Pandai Besi 


\section{Pendahuluan}

Istilah 'indigenous tourism' telah menjadi kajian akademisi atau penulis bidang pariwisata melalui publikasi ilmiah baik jurnal maupun buku rujukan ilmiah khususnya karya ilmiah berbahasa Inggris (Goodwin 2007, Ryan 2005, Sinclair 2003, Weaver 2010). Dapat dikatakan bahwa istilah indigenous tourism bukanlah istilah baru jika dilihat dari publikasi-publikasi ilmiah tersebut. Penulis mencoba mencari padanan atau arti yang tepat yang mungkin dapat digunakan dalam konteks bahasa Indonesia yang mengacu pada istilah indigenous tourism. Indigenous dapat diartikan sebagai pribumi, keaslian atau yang asli. Indigenous sering dikaitkan dengan masyarakat dengan menggunakan frase "indigenous people" yang mengacu pada kelompok masyarakat pribumi atau masyarakat asli suatu wilayah geografis atau dalam wilayah suatu destinasi pariwisata. Dari penggunaan indigenous people tersebut, istilah indigenous tourism muncul dan dapat menjadi alternatif bagi pemerintah daerah dalam mengembangkan pariwisata.

Indigenous people di negara-negara di dunia dapat menjadi contoh dalam memahami makna indigenous people dan indigenous tourism. Kebudayaan suku Aborigin di Australia misalnya, menjadi salah satu daya tarik wisata yang ditunjukkan dengan display kebudayaan suku Aborigin di museum. Suku Maori di New Zealand juga menjadi salah satu daya tarik wisata unggulan negara tersebut. Suku Maori adalah suku pribumi yang mendiami negara tersebut yang masih ada (eksis) hingga saat ini. New Zealand menjadikan kebudayaan suku Maori sebagai penunjang utama pariwisata negara tersebut (Amoamo \& Thompson 2010, Cukier \& Haas 2000, Dwyer 2012, McIntosh et al. 2004). Dalam konteks Indonesia dan Sulawesi Selatan secara khusus, suku Bugis, Makassar dan Toraja dapat dikatakan sebagai suku asli atau indigenous people Sulawesi Selatan yang kemudian menjadi potensi kepariwisataan Sulawesi Selatan.

Seiring dengan potensi indigenous tourism yang dimiliki provinsi Sulawesi Selatan, daerah-daerah atau kabupaten dan kota yang ada perlu memaksimalkan eksistensi indigenous tourism sebagai alternatif mengembangkan pariwisata daerah. Kabupaten Selayar secara khusus yang lebih dikenal sebagai Pulau Selayar dan dengan potensi maritimnya perlu melirik atau mengembangkan pariwisata alternatif selain jenis wisata bahari. Posisinya sebagai wilayah dengan pulau-pulau menjadikan destinasi ini memanfaatkan event kebaharian dalam menarik wisatawan berkunjung ke destinasi tersebut. Sebaliknya, jenis wisata lain nampaknya belum menjadi prioritas meskipun potensi budaya juga ada di wilayah ini.

Pemahaman akan arti dan konsep indigenous tourism dapat menjadi alasan belum dioptimalkannya jenis wisata ini. Promosi potensi budaya daerah telah menjadi perhatian dengan dimasukkannya event budaya serta potensi kebudayaan daerah melalui brosur-brosur pariwisata. Namun, terbatasnya informasi atau kajian mengenai konsep indigenous tourism serta pemahaman mengenai indigenous tourism menjadikan daerah-daerah wisata atau destinasi wisata hanya terfokus pada mempromosikan budaya daerah. Konsep pengembangan indigenous tourism nampaknya masih mengikat pada pariwisata secara umum tanpa ada langkah-langkah khusus pengembangan indigenous tourism daerah.

Potensi pariwisata suatu wilayah yang variatif dapat menjadi alasan wisatawan untuk tinggal lebih lama di suatu destinasi. Perbedaan motivasi wisatawan dan kebutuhan yang bervariasi akan eksplorasi suatu wilayah dapat menjadi alasan mengapa indigenous tourism perlu dikembangkan. Menurut D'Hauteserre (2010), terdapat kebudayaan atau aset wisata yang terdapat di suatu destinasi wisata yang dapat memberikan pengalaman yang variatif bagi wisatawan yang mungkin belum terungkap atau dieksplor secara maksimal. Pengalaman ini dapat menjadi promosi bagi suatu destinasi jika wisatawan mendapatkan kesan positif khususnya yang berkaitan dengan indigenous people dan atau indigenous tourism. Tujuan pengembangan pariwisata adalah memberikan kesempatan kepada masyarakatnya untuk mendapatkan nilai ekonomis khususnya bagi masyarakat asli (pribumi) (Burns 2005, Salazar 2012, Sofield 1993) yang kebudayaannya dimanfaatkan untuk tujuan pariwisata. Latar belakang penelitian ini menjadi alasan atau justifikasi pentingnya melakukan penelitian 
bidang pariwisata yang mengkaji tentang bagaimana mengidentifikasi potensi indigenous tourism, merekomendasikan langkah-langkah strategis dalam mengembangkan konsep indigenous tourism serta mengusulkan upaya yang dapat dilakukan oleh para stakeholder di Kabupaten Selayar.

Penelitian ini difokuskan pada eksistensi Perkampungan Bitombang dan Pandai Besi dalam konteks mengembangkan indigenous tourism di Kabupaten Selayar. Karena itu, rumusan masalah penelitian ini adalah 1) bagaimana potensi Perkampungan Bitombang dan Pandai Besi dalam mendukung indigenous tourism di Kabupaten Selayar? 2) bagaimana tahap atau langkah-langkah strategis dalam menunjang Kabupaten Selayar melalui konsep indigenous tourism? 3) upaya apa yang harus dilakukan oleh stakeholder daerah dalam mencapai tujuan pengembangan dan penyeimbangan indigenous tourism dan pariwisata berkelanjutan (sustainable tourism)?

Bentuk-bentuk, tipe atau jenis-jenis pariwisata sangat beragam jika ditinjau dari berbagai aspek, misalnya pariwisata budaya (cultural tourism), pariwisata kesehatan (health tourism), pariwisata bisnis (business tourism), pariwisata pegunungan (mountain tourism), pariwisata desa (rural tourism) yang merupakan bagian atau tidak dipisahkan dari ekowisata (ecotourism), pariwisata event dan gastronomi (event and gastronomi tourism), wisata olahraga (sport tourism) dan berbagai jenis atau bentuk-bentuk pariwisata dilihat dari tujuan wisatawan melakukan perjalanan. Indigenous tourism secara khusus menjadi salah satu bentuk atau alternatif jenis pariwisata yang layak untuk dikembangkan di suatu destinasi (Saarinen 2013, Smith \& Eadington 1992, Weaver 2010).

Beberapa akademisi mengemukakan definisi indigenous tourism. Hinch dan Butler (1996:9) mengemukakan bahwa indigenous tourism adalah "tourism activity in which indigenous people are directly involved eiher through control and/or by having their culture serve as the essence of the attraction". Definisi ini menekankan bahwa masyarakat asli atau pribumi di suatu destinasi adalah pihak yang secara langsung terlibat dalam aktivitas pariwisata melalui peran keterlibatan, pengelolaan atau kontrol terhadap sumber pariwisata di suatu destinasi. Mengingat kebudayaan masyarakat pribumi (culture of indigenous people) dimanfaatkan sebagai daya tarik wisata utama dalam destinasi tersebut, maka merekalah yang seharusnya berperan aktif sebagai pengelola dan pengontrol kegiatan pariwisata. Peran aktif indigenous people tersebut tidak semata-mata sebagai pekerja, tetapi merekalah yang memiliki hak dalam mengatur, mengembangkan dan memperoleh manfaat dari pemanfaatan kebudayaan mereka sebagai daya tarik wisata.

Smith (1996) berpendapat bahwa indigenous tourism adalah "segment of the visitor industry which directly involves native peoples whose ethnicity is a tourist attraction". Smith berpandangan bahwa potensi etnis (ethnicity) adalah daya tarik wisata utama yang dikunjungi oleh wisatawan. Sesungguhnya, etnis tidak terlepas dari kebudayaan sehingga dapat dikatakan bahwa indigenous tourism menjadikan kebudayaan asli (etnis) dari suatu masyarakat pribumi di destinasi wisata sebagai daya tarik wisata. Selanjutnya, industri pariwisata memanfaatkan keunikan dan daya tarik suatu suku pribumi untuk menarik wisatawan dengan tujuan yang variatif, misalnya untuk penelitian atau kajian kebudayaan, mendapatkan pengalaman dari suatu kelompok masyarakat, ataupun melihat secara langsung kehidupan masyarakat asli suatu destinasi wisata.

Indigenous people sesungguhnya sulit untuk dipahami atau didefinisikan. Hal ini didasarkan pada alasan bahwa batas-batas indigenous people tidak jelas. Bagaimana memahami bahwa seseorang atau kelompok masyarakat suatu destinasi merupakan indigenous people. Waitt (1999) berpandangan bahwa indigenous people dipahami sebagai kelompok masyarakat atau individu yang dapat dilihat dari sukunya, klan atau bangsanya. Hinch (2004:246) memberikan argumentasi bahwa "indigenous people is increasingly used in reference to communities, peoples, and nations that have historical continuity with pre-invasion and pre-colonial societies". Indigenous people dapat diidentifikasi berdasarkan aspek kesejarahan yang berkaitan dengan kedudukannya atau eksistensi baik sebelum adanya invasi maupun setelah masa penjajahan. Sebagai contoh, masyarakat Bugis Makassar yang mendiami pulau Sulawesi (atau Sulawesi Selatan secara khusus) dapat dikategorikan sebagai indigenous people karena mereka telah ada (eksis) sebelum adanya kolonisasi hingga kehidupan di 
Sulawesi Selatan saat ini. Dengan kata lain, mereka memiliki kaitan kesejarahan ditinjau dari segi suku atau bangsanya.

Meskipun definisi indigenous people ini mungkin saja masih menjadi perdebatan akan makna dan batas-batasnya (atau siapa yang dikategorikan atau tidak dikategorikan sebagai indigenous people), penelitian ini menekankan pada masyarakat suatu destinasi yang telah mendiami suatu destinasi yang dengan kebudayaannya (etnisitas) dimanfaatkan sebagai daya tarik wisata. Dari definisi indigenous tourism sebelumnya dapat dipahami bahwa indigenous tourism merupakan bagian dari pariwisata budaya (cultural tourism). Ini berarti bahwa cakupan indigenous tourism cukup luas karena memanfaatkan budaya dengan berbagai manifestasinya sebagai daya tarik wisata yang dikunjungi oleh wisatawan. Kunjungan ke pusat-pusat budaya, heritage, museum, galeri seni dan budaya, tur (tour) tentang kebudayaan dan berbagai bentuk tur atau perjalanan mengunjungi dan mempelajari aktivitas masyarakat pribumi di suatu destinasi merupakan cakupan dari indigenous tourism.

Jika pemangku kepentingan (stakeholder) pariwisata berkeinginan mengembangkan indigenous tourism, maka potensi daerah dengan kebudayaan masyarakat asli (pribumi) suatu destinasi merupakan basis utama yang harus dilestarikan. Tentunya, potensi keunikan, keragaman dan daya tarik wisata yang dapat menarik wisatawan berkunjung ke destinasi wisata merupakan bagian tak terpisahkan dari konsep indigenous tourism. Stakeholder yang dimaksud di sini adalah mereka yang memiliki hak dan kapasitas untuk berpartisipasi dan mendapatkan dampak dari aktivitas pariwisata (Gray 1989, Aas et al. 2005). Secara spesifik, stakeholder dapat dilihat dari empat aspek yakni wisatawan (tourists), masyarakat setempat (the host population), industri pariwisata (the tourism industry), pemerintah (the government agencies) (Mason 2003). Dalam konteks penelitian ini, stakeholder difokuskan pada masyarakat setempat, pemerintah dan industri pariwisata.

Indigenous tourism sering disandingkan dengan pariwisata berkelanjutan (sustainable tourism). Uraian definisi sebelumnya menjelaskan bahwa pelestarian kebudayaan masyarakat suatu destinasi (kebudayaan masyarakat pribumi/asli) merupakan inti dari indigenous tourism. Selain itu, masyarakat pribumi yang dalam beberapa hal tidak memiliki kemampuan, keterampilan dan kekuatan untuk terlibat dalam kegiatan pariwisata menjadi target utama dalam hal manfaat kegiatan pariwisata. Sejalan dengan itu, pariwisata berkelanjutan juga memandang bahwa pelestarian alam dan budaya serta kemanfaatan pariwisata untuk masyarakat destinasi menjadi pijakan utama pariwisata (Junaid 2015, Moscardo 2003, Griffin 2002, Mowforth \& Munt 2016). Karena itu, terdapat kesamaan tujuan dan targat antara indigenous tourism dan pariwisata berkelanjutan.

Organisasi pariwisata dunia (WTO) memberikan definisi pariwisata berkelanjutan sebagai jenis pariwisata "a form of tourism that meets the needs of the present tourists and host regions while protecting and enhancing opportunities for the future...leading to management of all resources in such a way that economic, social, and aesthetic needs can be fulfilled while mintaining cultural integrity, essential ecologial processes, biological diversity, and life support systems" (Marschall 2012:725). Pariwisata berkelanjutan diartikan sebagai jenis pariwisata yang diperuntukkan bagi pemenuhan kebutuhan wisatawan dan masyarakat di suatu destinasi dengan mendorong kesempatan bagi generasi mendatang untuk mendapatkan kesempatan dan pemenuhan yang sama. Hal ini diartikan sebagai pemanfaatan aset alam dan budaya untuk kepentingan manusia tanpa mengabaikan kemanfaatan bagi generasi mendatang.

Pariwisata berkelanjutan juga memfokuskan pada pengelolaan semua sumber-sumber pariwisata di mana kebutuhan ekonomi, sosial dapat terpenuhi dengan catatan penggunaan sumber-sumber pariwisata tersebut tetap mempertahankan integritas budaya, terjaganya proses ekologi atau pelestarian lingkungan serta mendukung berlangsungnya sistem kehidupan yang diharapkan dan seimbang. Murphy \& Price (2005) berpandangan bahwa pariwisata berkelanjutan dapat dipahami dalam tiga dimensi yakni dimensi pentingnya pengelolaan sumber-sumber pariwisata (resource management), dimensi kegiatan ekonomi, dimensi kewajiban sosial (social obligations). Ketiga dimensi ini tidak dapat dipisahkan satu sama lain karena pariwisata berkelanjutan suatu wilayah 
sebagai destinasi wisata akan terlihat dari keberlanjutan dimensi-dimensi tersebut.

Wisatawan memiliki motivasi dan kecenderungan yang berbeda-beda ketika berkunjung ke suatu destinasi. Mason (2003) membagi motivasi wisatawan mengadakan perjalanan ke dalam tiga motivasi utama yakni untuk bersenang-senang (pleasure) misalnya karena alasan budaya, olahraga, mengunjungi teman atau kolega; untuk tujuan professional (professional), misalnya pertemuan, melaksanakan misi, bisnis, dll.; untuk tujuan lain (other purposes) misalnya, untuk studi, tujuan kesehatan, dsb. Indigenous tourism adalah bentuk pariwisata yang menawarkan pengalaman unik bagi wisatawan mengenai kehidupan sosial budaya suku asli suatu destinasi. Bagi wisatawan pencinta budaya atau ingin mengalami pengalaman budaya masyarakat suatu destinasi, maka mereka lebih cenderung untuk mengeluarkan atau membelanjakan uang lebih banyak ketika berada di destinasi (more expenditure) (Hall \& Page 2006).

Mengingat indigenous tourism adalah alternatif pengembangan pariwisata bagi suatu destinasi, maka dibutuhkan strategi atau upaya agar pariwisata alternatif tersebut dapat dioptimalkan untuk kepentingan masyarakat destinasi. Selain itu, pariwisata alternatif tersebut memberikan andil terhadap pengembangan perekonomian masyarakat pribumi dan pelestarian sumber-sumber pariwisata. Friel (2008) mengemukakan bahwa kesadaran masyarakat akan pentingnya nilai-nilai warisan budaya (kebudayaan) untuk pengembangan dan keterlibatan masyarakat dalam hal pengelolaan dan kontrol menjadi sangat penting bagi suatu destinasi yang ingin mengembangkan strategi pengembangan pariwisata. Ini berarti bahwa strategi pariwisata disusun dengan prinsip bagaimana meningkatkan kesadaran indigenous people mengenai potensi pariwisata.

Verbeke \& Russo (2008) mengusulkan pentingnya dinamisasi masyarakat tradisional, mengangkat kualitas hidup masyarakat, mengangkat kebanggaan masyarakat sebagai potensi yang perlu dikembangkan dan mengangkat pengetahuan tradisional masyarakat untuk menghasilkan produkproduk yang dapat memberikan kesan bagi wisatawan. Dinamisasi diartikan sebagai proses identifikasi potensi etnis atau budaya masyarakat pribumi untuk kepentingan masyarakat kontemporer. Masyarakat akan menjadi bangga dengan potensi budaya mereka yang kemudian memberikan nilai tambah (added value) bagi masyarakat pemilik budaya itu sendiri. Selanjutnya, keunikan budaya tersebut perlu ditanamkan ke wisatawan dalam bentuk pemberian souvenir atau cenderamata yang lahir dari pengetahuan tradisional masyarakat pribumi.

\section{Metode Penelitian}

Penelitian dilakukan di Kabupaten Selayar pada bulan Juli 2016. Pendekatan studi kasus menuntun penulis dalam memahami konteks indigenous tourism yang ada di wilayah tersebut. Studi kasus merupakan feature atau bagian dari penelitian kualitatif (Denzin \& Lincoln 1994). Metode pengumpulan data dalam penelitian ini didasarkan pada prinsip metode kualitatif. Metode-metode kualitatif digunakan untuk menjawab pertanyaan penelitian yang berkaitan dengan eksplanasi fenomena sosial yang ada di lapangan (Beeton 2005, Richards \& Munsters 2010, Ritchie \& Lewis 2003). Fenomena sosial yang dimaksud dalam penelitian ini adalah fenomena sosial baudaya kepariwisataan khususnya yang berkaitan dengan indigenous tourism.

Indigenous tourism tidak terlepas dari masyarakat dengan kebudayaannya sebagai basis atau dasar dari eksistensi indigenous tourism. Pemilihan Kabupaten Selayar sebagai studi kasus didasarkan pada pertimbangan bahwa aktivitas pariwisata di destinasi ini terfokus pada pariwisata bahari, namun sesungguhnya memiliki potensi atau peluang untuk dikembangkan berdasarkan konsep indigenous tourism. Dalam penelitian ini, penulis memanfaatkan data kualitatif dalam memahami realita sosial yang ada di Kabupaten Selayar.

Metode pengumpulan data dilakukan melalui wawancara ke masyarakat, staf pemerintah bidang pariwisata serta kelompok masyarakat yang memiliki pemahaman mengenai kondisi kepariwisataan, sosial budaya masyarakat di Kabupaten Selayar. Delapan informan yang terdiri dari 4 (empat) orang 
pegawai Dinas Pariwisata Kabupaten Selayar, 2 (dua) orang masyarakat yang mendiami sekitar daya tarik wisata dan 2 (dua) orang masyarakat (atau pemerhati pariwisata) yang merupakan penduduk asli Kabupaten Selayar. Selanjutnya, kunjungan ke Kabupaten Selayar dan daya tarik wisata (observasi) khususnya ke Perkampungan Tua Bitombang dan Pandai Besi memberikan informasi penting tentang kondisi faktual dan bagaimana potensi daya tarik wisata seharusnya dikembangkan berdasarkan konsep indigenous tourism. Penulis juga menganalisis informasi atau data yang tertuang dalam rencana strategis pariwisata oleh Dinas Kebudayaan dan Pariwisata Kabupaten Selayar. Data dianalisis dengan menerapkan prinsip analisis data kualitatif sebagaimana diuraikan oleh Sarantakos (2013) yakni proses reduksi data, pengorganisasian dan interpretasi untuk menghasilkan simpulan penelitian.

\section{Hasil Penelitian dan Pembahasan}

\section{Masyarakat, budaya dan pariwisata di Kabupaten Selayar}

Kabupaten Selayar atau Pulau Selayar sangat dikenal dengan Tana Doang yang berarti tanah tempat orang berdoa. Istilah Tana Doang tersebut cenderung dikaitkan dengan aktivitas para pelaut di zaman ketika Selayar menjadi salah satu bandar atau pelabuhan untuk tujuan perniagaan para pedagang dan pelaut. Pemerintah Kabupaten Selayar melalui website pemerintah daerah menyebutkan bahwa "di masa lalu, Pulau Selayar menjadi tempat berdoa bagi para pelaut yang hendak melanjutkan perjalanan baik ke barat maupun ke timur untuk keselamatan pelayaran mereka" (Pemerintah Kabupaten Selayar). Ini menjadi informasi bahwa eksistensi Kabupaten Selayar yang menjadi tujuan utama perdagangan dan pelayaran para pelaut telah dikenal sejak lama. Istilah Tana Doang mungkin menjadi frase yang tepat untuk menggambarkan bahwa Tanah Selayar menjadi pusat kegiatan religius bagi para pelaut di zamannya.

Istilah Tana Doang menjadi menarik ketika pemandu penulis menjelaskan bahwa beberapa tokoh atau orang-orang penting memanfaatkan Tanah Selayar sebagai lokasi untuk berdoa untuk mencapai tujuan dan cita-cita mereka. Meskipun pemandu penulis tidak menyebutkan siapa-siapa tokoh atau orang-orang penting tersebut, Tana Selayar telah menjadi salah satu pilihan untuk dikunjungi dengan tujuan khusus. Dalam konteks pariwisata, ini dapat menjadi daya tarik wisatawan untuk mengunjungi destinasi melalui pendekatan aktivitas bersenang-senang yang dibarengi dengan daya tarik yang lainnya, misalnya, cerita tentang kisah-kisah Tana Doang tersebut.

Mengingat Kabupaten Selayar sebagai wilayah persinggahan bagi kapal-kapal para pelaut, dapat dipahami bahwa masyarakat yang mendiami Kabupaten Selayar tidak terlepas dari kehidupan kebaharian. Masyarakat yang mendiami wilayar pesisir pantai memanfaatkan potensi alam untuk kehidupan mereka, misalnya sebagai nelayan, perkebunan dengan kelapa sebagai produk utama. Ketika menyusuri wilayah kabupaten Selayar, penulis berpandangan bahwa potensi pohon kelapa di sepanjang perjalanan dengan kehidupan masyarakatnya yang memanfaatkan kelapa tersebut dapat mendorong Selayar sebagai pulau kelapa (coconut island). Pariwisata Selayar sesungguhnya dapat terbantu dan berkembang dengan memaksimalkan coconut island sebagai salah satu penarik bagi wisatawan.

Pariwisata Selayar sangat dikenal dengan pariwisata bahari dengan penyelenggaraan event nasional (bahkan internasional) ekspedisi Takabonerate, sebuah pulau yang menjadi lokasi pelaksanaan event tersebut. Pemerintah Kabupaten Selayar mengungkapkan "Kabupaten Selayar memiliki keunggulan dalam pengelolaan pariwisata bahari khususnya diving karena dapat dilakukan sepanjang tahun, ...potensi dalam pengelolaan pesisir dan pulau-pulau kecil untuk wisata bahari merupakan keunggulan kompetitif" (Panduan wisata Selayar, tanpa tahun).

Potensi budaya juga telah dipromosikan sebagai daya tarik wisata daerah tersebut misalnya, tari Pakarena, pertunjukan seni Rambang-Rambang, kesenian tradisional dengan melabuhkan perahu nelayan ke pantai Selayar, kesenian tradisional Dide', ritual budaya tahunan A'dinging-dinging. 
Dalam hal wisata budaya dan sejarah, eksistensi Gong Nekara, jangkar kuno raksasa dan masjid Tua Gantarang dan perkampungan unik Bitombang telah menjadi daya tarik wisata yang dipromosikan oleh pemerintah daerah melalui Dinas Kebudayaan dan Pariwisata. Potensi kebudayaan tersebut perlu mendapat perhatian utama agar kebudayaan tidak hanya menjadi pengikut dan penunjang, tetapi sebagai daya tarik wisata utama selain potensi bahari.

Dalam memahami masyarakat di Kabupaten Selayar, eksistensi kelompok masyarakat yang ada di daerah tersebut sebelum penjajahan Belanda dan Jepang merupakan indigenous people di wilayah tersebut. Dilihat dari bahasa masyarakatnya (Bahasa Selayar), terdapat kesamaan atau kemiripan dalam hal kosakata dengan bahasa Makassar, Bugis dan Mandar. Penulis dapat memahami beberapa kata dan ungkapan bahasa dari indigenous people ketika mereka melakukan komunikasi. Hal ini mengindikasikan bahwa kebudayaan indigenous people memiliki keterkaitan dengan budaya Bugis dan Makassar. Lokasinya sebagai tempat persinggahan bagi para pelaut memungkinkan terdapat interaksi kebudayaan antara pendatang dan penduduk setempat. Jadi, indigenous people di Kabupaten Selayar dapat dipahami dari bahasa, adat istiadat yang mereka anut secara turun temurun dan aspek kesejarahan kelompok masyarakat tersebut.

Gelar Opu menjadi salah satu gelar yang diberikan kepada kepala pemerintahan yang pertama kali terbentuk di wilayah Selayar. Hal ini menjadi penanda awal mula pemerintahan di wilayah tersebut yang berarti pemerintahan tidak dimulai oleh penjajahan Belanda dan Jepang, akan tetapi lahir dari masyarakat pribumi itu sendiri. Salah satu ciri khas dari kebudayaan pribumi (indigenous culture) masyarakat Selayar adalah penggunaan istilah-istilah seperti tetta (ayah), amma' (ibu), anak, menantu, ampung (cucu), daeng (kakak), aring (adik), purina (paman/bibi), kakek dan nenek dalam kehidupan keseharian mereka. Ini berarti bahwa mereka yang tinggal di wilayah tersebut memiliki keterkaitan historis dan budaya dengan masyarakat yang telah mendiami kepulauan Selayar sebelum masa penjajahan. Dengan demikian, potensi indigenous tourism adalah segala yang menjadi daya tarik wisata yang memanfaatkan potensi budaya dan etnis masyarakat Selayar.

\section{Eksistensi perkampungan tua Bitombang dan pandai besi dalam kerangka pengembangan indigenous tourism}

KetikaberkunjungkekantorDinasKebudayaan dan PariwisataKabupaten, parastafmerekomendasikan untuk mengunjungi Perkampungan Tua Bitombang (Bitombang Old Village) yang berlokasi sekitar 7 km dari kota Benteng, ibukota Kabupaten Selayar. Dari namanya, perkampungan ini menjadi tujuan utama peneliti dalam memahami dan mengamati secara langsung kondisi faktual potensi daya tarik wisata berbasis indigenous tourism. Dari brosur yang diberikan staf pemerintah setempat, gambar rumah dengan tiang yang tinggi menjadi ciri khas perkampungan Tua Bitombang dan menjadi gambar utama dan terdepan di brosur tersebut.

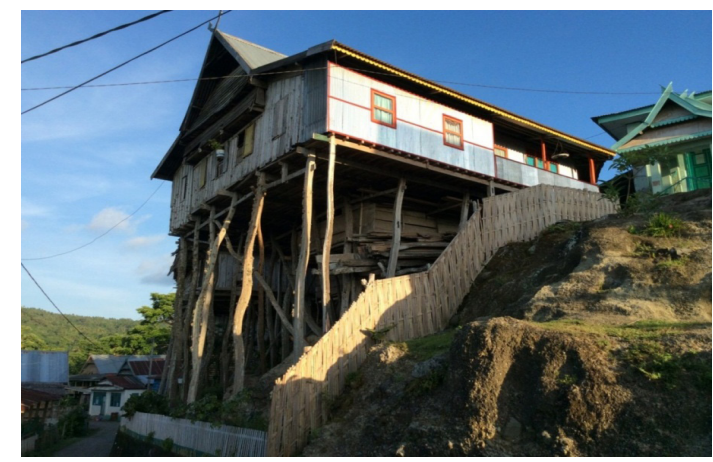

Gambar 1.

Rumah tradisional di Perkampungan Tua Bitombang

Sumber: Data pribadi 2016 
Kondisi tanah (topografi alam) yang tidak merata di daerah ini menjadi alasan mengapa bentuk rumah yang ada di perkampungan tersebut dibangun dengan menyesuaikan kondisi tanah. Dari gambar di atas (gambar 1) nampak bahwa bagian belakang rumah tersebut memiliki tiang yang cukup tinggi (dapat mencapai hingga 12 meter) dan bagian depan sekitar 1 hingga 2 meter. Ketika memasuki wilayah perkampungan tersebut, penulis melihat bahwa bagian belakang rumah berada di depan (di pinggir jalan raya) yang berarti bahwa bagian bawah dapur dan bagian belakang rumah dapat dilihat oleh pengunjung. Tiang rumah tradisional tersebut memanfaatkan kayu dari pohon (kayu bitti'/ kolasa) dengan usia yang dapat mencapai hingga ratusan tahun. Masyarakat di Kabupaten Selayar meyakini bahwa keberadaan rumah tradisional ini memiliki kaitan dengan usia penduduknya yang cukup panjang (hingga di atas 90 tahun) karena rumah (perkampungan) tersebut memiliki berkah (barakka') dengan eksistensi tiang yang tinggi dan usia penduduknya yang panjang.

Keberadaan Perkampungan Tua Bitombang dapat menjadi ikon dan penarik wisatawan untuk datang ke Selayar. Sesungguhnya, banyak informasi dan kajian yang menarik yang dapat dilihat dan diketahui oleh pengunjung dengan rumah tradisional tersebut. Hal ini sejalan dengan makna dan tujuan indigenous tourism, memanfaatkan etnis atau potensi budaya masyarakat pribumi sebagai pendorong dan penarik wisatawan. Di Perkampungan Tua Bitombang, masyarakatnya masih mempertahankan aktivitas tradisional dalam rangka mempertahankan kehidupan mereka. Aktivitas bertani dan kehidupan dengan nuansa alamiah masih tetap terjaga sehingga dapat menjadi motivasi bagi wisatawan untuk mengetahui makna dan falsafah hidup masyarakat lokal (pribumi) dalam konteks pariwisata dengan minat atau tujuan memahami kehidupan sosial budaya masyarakat destinasi.

Kehidupan masyarakat pandai besi belum dilirik sebagai daya tarik wisata di daerah Selayar. Informasi pariwisata dalam bentuk tertulis tentang potensi ini belum dibuat oleh pemerintah setempat. Penulis memanfaatkan kunjungan ke Selayar untuk melihat langsung pelaku pandai besi sebagai aktivitas beberapa kelompok masyarakat asli Kabupaten Selayar (lihat gambar 2). Selanjutnya, masyarakat pandai besi menyambut baik kehadiran peneliti dan memahami bahwa pengunjung yang datang ingin melihat bagaimana peralatan-peralatan yang terbuat dari besi yang digunakan di kehidupan modern dibuat oleh masyarakat secara tradisional.

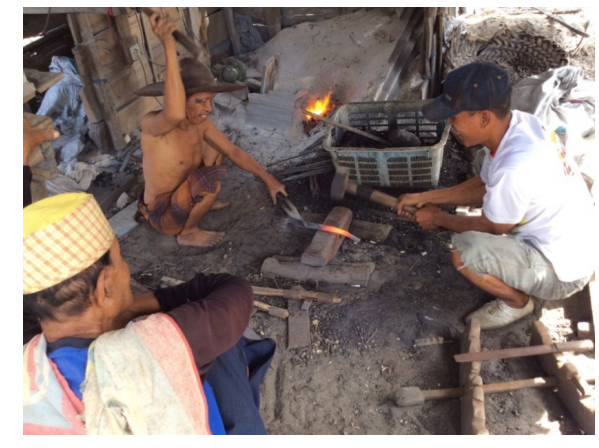

Gambar 2.

Pandai besi di Kabupaten Kepulauan Selayar

Sumber: Data pribadi 2016

Keunikan dan aktivitas masyarakat pandai besi dapat menjadi penarik wisatawan lokal dan internasional. Hal ini didasarkan pada alasan bahwa sesuatu yang belum pernah dilihat oleh wisatawan atau tidak ada di tempat mereka tinggal atau berada menjadi pendorong untuk mengetahui kebudayaan masyarakat destinasi. Wisatawan dengan tujuan melihat aktivitas masyarakat merupakan target utama indigenous tourism. Eksistensi pandai besi sebaiknya dioptimalkan dengan peran pemerintah daerah memasukkan potensi ini dalam konteks pengembangan indigenous tourism. 


\section{Langkah (tahap) pengembangan indigenous tourism}

Dari hasil wawancara, observasi dan telaah dokumen dan publikasi ilmiah, peneliti mengusulkan beberapa tahap ataupun pendekatan dalam mengembangkan indigenous tourism. Langkah pertama yang seharusnya dilakukan adalah melakukan kajian atau penelitian tentang sejarah dan nilai-nilai budaya yang terkait dengan indigenous people dan potensi etnis dan kebudayaan yang dimiliki. Dalam beberapa hal, terdapat kecenderungan bahwa masyarakat dan stakeholder pariwisata lainnya di daerah hanya membanggakan potensi budaya indigenous people tanpa melihat pentingnya kandungan atau informasi yang seharusnya diperoleh oleh wisatawan ketika mereka mengunjungi daya tarik wisata. Indigenous tourism mendorong pengunjung atau wisatawan memahami makna dan filosofi kehidupan masyarakat lokal ketika mereka berkunjung.

Dari hasil kajian ilmiah atau peneliti tersebut, dihasilkan buku atau panduan informasi kebudayaan dan sejarah masyarakat setempat (indigenous people). Tim pengkaji atau peneliti ini diharapkan merupakan gabungan atau tim kerja dengan latar belakang atau ahli di bidang sejarah, kebudayaan, pariwisata, perwakilan pemerintah dan masyarakat asli (indigenous people) yang memiliki pengetahuan dan pengalaman mengenai Kabupaten Selayar. Selanjutnya, tim ini diharapkan membantu atau memfasilitasi pemberian modal pengetahuan dan keterampilan kepada masyarakat lokal mengenai informasi sejarah dan pengetahuan tentang kebudayaan (etnis) masyarakat setempat. Buku panduan atau pedoman tersebut akan digunakan sebagai rujukan ilmiah bagi pemandu wisata lokal, masyarakat dan pemerintah dalam menjelaskan informasi tentang kebudayaan indigenous people ke wisatawan.

Langkah kedua yang dapat dilakukan adalah pemerintah menginisiasi pembentukan organisasi pencinta lingkungan, budaya dan pariwisata di bawah koordinasi aktif oleh pemerintah dari berbagai Satuan Kerja Perangkat Daerah (SKPD). Organisasi ini beranggotakan masyarakat di Kabupaten Selayar dari latar belakang yang berbeda-beda. Sesungguhnya, kebanyakan daerah di Sulawesi Selatan (termasuk Kabupaten Selayar) telah mengembangkan kelompok sadar wisata meskipun peran dan fungsinya mungkin belum maksimal.

Organisasi yang terbentuk ini didorong untuk menyelenggarakan kegiatan yang bersifat meningkatkan kesadaran masyarakat akan pentingnya pelestarian budaya masyarakat lokal, lingkungan dan pariwisata. Organisasi ini pula dapat mendorong masyarakat untuk bekerja secara sukarela (volunteer) untuk membantu kegiatan-kegiatan organisasi. Selain itu, fungsi promosi pariwisata dapat dijalankan dengan memerhatikan tujuan memperkenalkan budaya dan potensi pariwisata daerah.

Langkah ketiga yang dapat dilakukan untuk mengembangkan indigenous tourism di Kabupaten Selayar adalah pentingnya membuat rute perjalanan bagi wisatawan yang dimulai dari kantor Dinas Kebudayaan dan Pariwisata sebagai pusat informasi pariwisata indigenous tourism. Rute perjalanan diartikan sebagai panduan bagi wisatawan dalam melakukan eksplorasi daya tarik wisata. Pemerintah daerah telah membuat lokasi atau informasi jarak antara satu daya tarik wisata ke daya tarik wisata lainnya. Namun, pembuatan rute perjalanan bagi wisatawan dapat dibagi ke dalam tiga bagian yakni wisatawan dengan tujuan mengeksplorasi alam, wisatawan budaya (indigenous tourism), dan rute gabungan atau menyeluruh agar wisatawan dapat lebih lama tinggal dalam memperoleh pengalaman wisata di kabupaten Selayar.

Indigenous tourism perlu menekankan bahwa pengalaman wisatawan terefleksikan dalam pemahaman terintegrasi mengenai nilai-nilai budaya yang dianut masyarakat suatu destinasi (Farrel \& Twinning 2005). Ini berarti bahwa wisatawan indigenous tourism mengharapkan memperoleh pengalaman yang menyeluruh mengenai nilai-nilai budaya masyarakat setempat. Rute perjalanan akan menuntun wisatawan budaya (indigenous tourism) untuk menentukan perjalanan dan memahami makna nilai-nilai budaya dalam konteks lingkungan sosial dan budaya masyarakat di Kabupaten Selayar. Rute perjalanan ini juga berkaitan dengan manajemen pengunjung (visitor management) agar pengunjung dapat memperoleh makna dan memberikan serta memperoleh interpretasi potensi budaya dari kunjungannya (Helmy \& Cooper 2008, Mason 2003). 
Indigenous tourism dan pariwisata berkelanjutan akan berjalan sesuai dengan tujuan dan target jika pemerintah sebagai stakeholder utama menjadikan pariwisata sebagai prioritas pengembangan dan masyarakat. Peran pemerintah dalam hal ini adalah sebagai fasilitator bagi berbagai kelompok masyarakat dalam memahami arti penting pengembangan pariwisata berkelanjutan dan indigenous tourism. Strategi melibatkan tokoh-tokoh penting daerah maupun orang-orang yang terkenal (misalnya artis atau aktor) dalam mempromosikan pariwisata menjadi salah satu upaya menyadarkan masyarakat. Dalam hal ini, mereka dapat menjadi agen atau duta pelestarian lingkungan alam, budaya dan pariwisata.

\section{Simpulan}

Kabupaten Kepulauan Selayar dikenal dengan potensi kebaharian khususnya pelaksanaan event skala nasional dan internasional, festival Takabonerate. Festival ini mampu mendatangkan wisatawan domestik dan internasional. Selain potensi bahari, kabupaten ini dapat mengoptimalkan eksistensi indigenous people dengan keunikan dan kekhasan kebudayaannya dalam konteks indigenous tourism. Perkampungan Tua Bitombang, Kampung Nelayan, Pandai Besi dan berbagai aktivitas indigenous people sesungguhnya dapat mendorong kemajuan pariwisata kabupaten Selayar. Pengunjung ataupun wisatawan dapat memperoleh pengalaman yang unik, khas dan berbeda dibandingkan kebudayaan mereka dengan mengunjungi daya tarik wisata ini. Tentunya, informasi tentang sejarah, nilai-nilai budaya masyarakatnya yang disampaikan oleh pemandu wisata lokal dapat memenuhi harapan wisatawan tersebut.

Kabupaten Kepulauan Selayar perlu menerapkan langkah-langkah strategis agar tujuan di atas dapat tercapai. Penelitian ini memandang bahwa perlu dibentuk tim peneliti yang bertugas untuk menyelidiki nilai-nilai sejarah dan budaya yang dimiliki masyarakat lokal (indigenous people) untuk dijadikan sebaga bahan atau rujukan ilmiah bagi masyarakat dan wisatawan sebelum indigenous tourism dikembangkan. Memahami makna dan filosofi kebudayaan indigenous people adalah salah satu tujuan indigenous tourism, karena itu, hasil tim tersebut dapat dibukukan dan dipublikasikan untuk kepentingan masyarakat.

Masyarakat perlu diarahkan untuk membentuk organisasi kemasyarakatan yang perhatian (concern) dengan isu-isu pelestarian lingkungan, budaya dan pariwisata agar mereka dapat fokus membantu pemerintah mengembangkan aset pariwisata daerah. Kesadaran masyarakat akan isu-isu tersebut masih rendah sehingga pembentukan organisasi ini akan menjadi pendorong dan fasilitator bagi berbagai kelompok atau lapisan masyarakat.

Selanjutnya, pemerintah daerah sebagai pemimpin (leader) untuk pengembangan pariwisata daerah bersama dengan kelompok stakeholder lainnya perlu membuat rute perjalanan yang mengatur dan menuntun wisatawan dalam mengeksplorasi destinasi dan daya tarik wisata. Rute perjalanan ini dapat membuat wisatawan untuk tinggal lebih lama di destinasi wisata. Tentunya, dukungan aksesibilitas, dan fasilitas menjadi unsur utama dalam menunjang pengembangan indigenous tourism. Pengalaman menyeluruh bagi wisatawan akan nilai-nilai budaya indigenous people serta kemanfaatan ekonomis bagi masyarakat lokal adalah prinsip utama indigenous tourism dan sustainable tourism sehingga kedua jenis pariwisata tersebut dapat berjalan dengan peran seluruh stakeholder yang ada di destinasi wisata.

\section{Daftar Pustaka}

Aas C, Ladkin A \& Fletcher J (2005) Stakeholder Collaboration and Heritage Management. Dalam: DJ Timothy (ed). Managing Heritage and Cultural Tourism Resources: Critical Essays. Farnham: Ashgate. 1-22.

Amoamo M \& Thompson A (2010) (Re)Imaging maori tourism: Representation and cultural hybridity in postcolonial New Zealand. Tourist Studies 10(1):35-55.

Beeton S (2005) The Case Study in Tourism Research: A Multi-Method Case Study Approach. Dalam: BW Ritchie, P Burns, \& C Palmer (eds). Tourism Research Methods: Integrating Theory with 
Practice. Wallingford: CABI. 37-48.

Burns P (2005) An Introduction to Tourism and Anthropology. London: Routledge.

Cukier J \& H.d. Haas Hd (2000) Maori Involvement in Tourism in The Waikato Region. Dalam: J Cukier \& E Dixon (eds). Tourism Resources, Impacts and Planning: Geographical Perspectives on New Zealand and International Tourism. Hamilton: Department of Geography University of Waikato New Zealand. 11-20.

Denzin NK \& Lincoln YS (1994) Handbook of Qualitative Research (1 $\left.1^{\text {st }} \mathrm{ed}\right)$. Sage: London.

D'Hauteserre A-M (2010) Government policies and indigenous tourism in New Caledonia. Asia Pacific Journal of Tourism Research. 15(3):285-303.

Dinas Kebudayaan dan Pariwisata Kabupaten Selayar. Brosur Pariwisata Kabupaten Kepulauan Selayar.

Dwyer T (2012) Sharing a Living Culture: The Guide's Role in Managing Maori Tourism Experiences. Future Times: 2 .

Farrel B \& Twinning-Ward L (2005) Seven steps towards sustainability: Tourism in the context of new knowledge. Journal of Sustainable Tourism 13(2):109-122.

Friel MM (2008) Heritage-Led Development of Rural Regions: A Case Study of South-Western Romania. Dalam: MJ Verbeke \& GK Priestley (eds). Cultural Resources for Tourism: Patterns, Processes and Policies. New York: Nova Science. 111-124.

Goodwin H (2007) Indigenous Tourism and Poverty Reduction. Dalam: R Butler \& T Hinch (eds). Tourism and Indigenous Peoples: Issues and Implications. Oxford: Elsevier. 84-94.

Gray B (1989) Collaboration Finding Common Ground for Multi-Party Problems. San Francisco: Josey Bass.

Griffin T (2002) An Optimistic Perspective On Tourism's Sustainability. Dalam R Harris, T Griffin \& P Williams (eds) Sustainable Tourism: A Global Perspective. Oxford: Butterworth-Heinemann. 24-32.

Hall CM \& Page SJ (2006) The Geography of Tourism and Recreation. London: Routledge.

Hassan F (2008). Heritage for Development: Concepts and Strategic Approaches. Dalam: F Hassan, A. d Trafford \& M Youssef (eds). Cultural Heritage and Development in the Arab World. Alexandria: The Bibliotheca Alexandrina. 13-52.

Helmy E \& C Cooper (2008) Sustainable Tourism Planning in the Arab World: The Egyptian Case. Dalam: F Hassan, Ad Trafford \& M Youssef (eds). Cultural Heritage and Development in the Arab World. Alexandria: The Bibliotheca Alexandrina. 175-204.

Hinch TD (2004) Indigenous People and Tourism. Dalam: AA Lew, CM Hall \& AM Williams (eds). A Companion to Tourism. Malden: Blackwell. 246-257.

Hinch T \& Butler R (1996). Indigenous Tourism: A Common Ground for Discussion. Dalam: T Hinch \& R Butler (eds). Tourism and Indigenous People. London: International Thomson Business Press.

Junaid I (2015) Sustainable tourism in Toraja: Perspective of indigenous people. Asean Journal on Hospitality and Tourism 14:45-55.

Marschall S (2012) Sustainable heritage tourism: The Inanda heritage route and the 2010 fifa world cup. Journal of Sustainable Tourism 20(5): 721-736.

Mason P (2003) Tourism Impacts, Planning and Management. Burlington: Butterworth-Heinemann.

McIntosh AJ, Zygadlo FK \& Matunga H (2004) Rethinking Maori. Asia Pacific Journal of Tourism Research 9(4): 331-352.

Moscardo G (2003) Interpretation and sustainable tourism: Functions, examples and principles. The Journal of Tourism Studies 14(1):112-123.

Mowforth M \& Munt I (2016) Tourism and Sustainability: Development, Globalisation and New Tourism in The Third World (4th ed). London: Routledge.

Panduan Wisata Kabupaten Selayar (Tanpa Tahun) Dinas Kebudayaan dan Pariwisata Kabupaten Kepulauan Selayar.

Ryan C (2005) Who Manages Indigenous Cultural Tourism Product-Aspiration and Legitimization. Dalam: C Ryan \& MAicken (eds) Indigenous Tourism: The Commodification and Management of Culture. Amsterdam: Elsevier. 69-74.

Richards G \& Munsters W (2010) Developments and Perspectives in Cultural Tourism Research. Dalam: G Richards \& W Munsters (eds) Cultural Tourism Research Methods. Wallingford: CABI. 1-12.

Saarinen J (2013) Indigenous Tourism and the Challenge of Sustainability. Dalam: M Smith \& G Richards (eds) The Routledge Handbook of Cultural Tourism. New York: Routledge. 220-226.

Salazar NB (2012) Community-based cultural tourism: Issues, threats and opportunities. Journal of Sustainable Tourism 20(1):9-22.

Sarantakos S (2013) Social Research (4th ed). New York: Palgrave Macmillan.

Website Resmi Pemerintah Kabupaten Kepulauan Selayar [Diakses pada tanggal 19 November 2016]. http://kepulauanselayarkab.go.id/sejarah.php. 
Sinclair D (2003) Developing indigenous tourism: challenges for the Guianas. International Journal of Contemporary Hospitality Management 15(3):140-146.

Sofield THB (1993) Indigenous tourism development. Annals of Tourism Research 20: 729-750.

Smith V \& Eadington WR (1992) Tourism Alternatives. Chichester: Wiley.

Smith V (1996) Hosts and Guests: The Anthropology of Tourism (2nd ed.). Philadelphia: The University of Pennsylvania.

Verbeke MJ \& Russo AP (2008) Heritage-Led Development of Rural Regions: A Case Study of SouthWestern Romania. Dalam: MJ Verbeke, GK Priestley \& AP Russo (eds) Cultural Resources for Tourism: Patterns, Processes and Policies. New York: Nova Science. 1-14.

Weaver D (2010) Indigenous tourism stages and their implications for sustainability. Journal of Sustainable Tourism 18(1):43-60.

Waitt G (1999) Naturalizing the "Primitive": A critique of marketing australia's indigenous peoples as "Hunter-Gatherers". Tourism Geographies 1(2):142-63.

Williams S (2009) Tourism Geography: A New Synthesis. London: Routledge. 